\title{
Management of bile acid malabsorption using low-fat dietary interventions: a useful strategy applicable to some patients with diarrhoea-predominant irritable bowel syndrome?
}

\author{
Authors: Lorraine Watson, ${ }^{\mathrm{A}}$ Amyn Lalji, ${ }^{\mathrm{B}}$ Shankar Bodla, ${ }^{\mathrm{C}}$ Ann Muls, ${ }^{\mathrm{D}} \mathrm{H}$ Jervoise N Andreyev ${ }^{\mathrm{E}}$ and Clare Shaw ${ }^{\mathrm{F}}$
}

\begin{abstract}
This study evaluates the efficacy of low-fat dietary interventions in the management of gastrointestinal (GI) symptoms due to bile acid malabsorption. In total, 40 patients with GI symptoms and a 7 -day ${ }^{75}$ selenium homocholic acid taurine (SeHCAT) scan result of $<20 \%$, were prospectively recruited and then advised regarding a low-fat dietary intervention. Before and after dietary intervention, patients rated their GI symptoms using a 10-point numerical scale, and recorded their intake in 7-day dietary diaries. After dietary intervention, the median scores for all GI symptoms decreased, with a significant reduction for urgency, bloating, lack of control, bowel frequency $(p \leq 0.01)$. Mean dietary fat intake reduced to $42 \mathrm{~g}$ fat after intervention $(p \leq 0.01)$. Lowfat dietary interventions in patients with a SeHCAT scan result of $<20 \%$ leads to clinically important improvement in GI symptoms and should be widely used.
\end{abstract}

KEYWORDS: Bile acid malabsorption, low-fat diet, SeHCAT

\section{Introduction}

Irritable bowel syndrome (IBS) is the most common bowel disorder seen in primary and secondary care, with an estimated prevalence in the general population of $10-20 \% .^{1,2}$ IBS causes a significant economic burden through the utilisation of healthcare resources and absenteeism from work. ${ }^{3,4}$ The

\footnotetext{
Authors: Adietitian, Department of Nutrition and Dietetics, The Royal Marsden NHS Foundation Trust, London, UK; B project manager, GI Unit, Department of Medicine, The Royal Marsden NHS Foundation Trust, London, UK; ' C statistician, Department of Statistics, The Royal Marsden NHS Foundation Trust, Sutton, UK; D nurse consultant in GI consequences of cancer, GI Unit, Department of Medicine, The Royal Marsden NHS Foundation Trust, London, UK; ${ }^{E}$ Consultant gastroenterologist, GI Unit, Department of Medicine, The Royal Marsden NHS Foundation Trust, London, UK; F Consultant dietitian, Department of Nutrition and Dietetics, The Royal Marsden NHS Foundation Trust, Fulham Road, London, UK
}

symptoms of IBS frequently have a negative impact on quality of life, ${ }^{4,5}$ with diarrhoea-predominant IBS (IBS-D) having potentially debilitating effects. ${ }^{5,6}$

At least $60 \%$ of patients told they have IBS-D are misdiagnosed and have missed organic disease (eg bile acid malabsorption (BAM), small bowel bacterial overgrowth, pancreatic insufficiency, coeliac disease and disaccharide intolerance). ${ }^{7}$ Bile acid diarrhoea (BAD) is the most commonly missed cause of IBS-like symptoms. ${ }^{8,9} \mathrm{BAD}$ is increasingly recognised following upper gastrointestinal (GI) surgery, including cholecystectomy, in diabetes mellitus and following pancreatitis. ${ }^{10,11}$ BAM also affects people with terminal ileal disease (eg Crohn's disease, after pelvic radiotherapy) or after surgical resection. ${ }^{10,11}$ More than $1 \%$ of the UK population have this condition. ${ }^{8,9}$

Bile is synthesised in the liver and stored in the gall bladder. Cholecystokinin, produced by enterendocrine cells in response to nutrients in the duodenum, stimulates contraction of the gallbladder and relaxation of the sphincter of Oddi, thereby releasing bile into the lumen of the small bowel. Feeding of high-fat meals, rich in long-chain triglycerides, to women subjects has been shown to increase blood levels of cholecystokinin and plasma bile acids. ${ }^{12}$ Conversely, bile acid production and release is reduced in subjects consuming a lower fat test meal or diet. ${ }^{13,14}$ Approximately 95\% of secreted bile is reabsorbed, mainly through an active uptake mechanism in the terminal ileum recirculated to the liver and reused several times a day. Bile acid production is regulated by fibroblast growth factor 19 (FGF19) which is produced in the terminal ileum. Disordered negative feedback of FGF19 leading to bile overproduction ${ }^{15,16}$ allows excessive bile to reach the colon, triggering electrolyte and water secretion, increased GI motility, shortening of the colon transit time and inhibition of water and electrolyte reabsorption, ${ }^{17,18}$ leading to unpredictable loose stools or watery diarrhoea and potentially steatorrhoea. ${ }^{17-19}$ The presence of excessive bile acids in the colon can also lead to abdominal pain, bloating, flatulence, urgency of defecation, nocturnal defecation and faecal incontinence..$^{10,19}$

The use of low-fat diets to improve symptoms in patients diagnosed with BAM has previously been described. ${ }^{20,21}$ However, this simple dietary approach to the management of a potentially huge population of patients with BAM or BAD is largely unknown. 
The aim of this study was to evaluate the efficacy of low-fat dietary interventions used in the management of GI symptoms due to BAM/diarrhoea, by monitoring the change in GI symptoms before and after a low-fat dietary intervention.

\section{Methods}

This prospective evaluation was approved by the local NHS hospital trust's clinical audit committee and did not to require informed signed consent from patients.

Patients were recruited if they were experiencing GI symptoms and were referred by their cancer specialist or GP and had a 7 -day ${ }^{75}$ selenium homocholic acid taurine (SeHCAT) scan result of $<20 \%$. They were then treated according to the algorithm shown in Fig 1. If patients required a bile acid sequestrant this was given and the dose optimised before receiving any dietary advice.

Patients were asked to complete a 7-day dietary diary (7DD), before their initial consultation with a registered dietitian and then asked to identify which of their GI symptoms, from a predetermined list, they would like to change and rate those GI symptoms. A verbally administered 10-point numerical rating scale, NRS-10, was used. ${ }^{22}$ Patients were then advised on a tailored low-fat dietary intervention, which aimed to provide $20 \%$ of total energy from fat. Patients attended a follow up with the dietitian 6-8 weeks later at which they brought a second 7DD and rated their GI symptoms again. The contents of the food diary were analysed using the Dietplan6 computer programme (ForestField Software Limited).

\section{Statistical analysis}

The median symptom scores for the group before and after dietary intervention were calculated, along with the minimum and maximum scores. The Wilcoxon signed-rank test was used to determine the difference in these scores before and after dietary intervention. Descriptive statistics were presented regarding the proportion of patients in each SeHCAT scan range and the proportion of patients reporting each GI symptom. The difference in the reported dietary fat and fibre intake, before and after dietary intervention, was determined using a t-test to specify the level of statistical significance. The percentage adherence to the low-fat dietary intervention was also calculated.

\section{Results}

\section{Baseline characteristics}

This study, carried out between April 2012 and July 2013 in a secondary care joint gastroenterology and nutrition clinic, recruited 20 men and 20 women with a mean age of 61 years (range 22-90; median 61; standard deviation 12). In total, $25(62.5 \%)$ patients were established on the bile acid sequestrant colesevelam (Sanofi Aventis) before receiving dietary advice. Table 1 shows the characteristics of patients included in this study at baseline.

Patients were not suitable for inclusion in this evaluation if they had already received low-fat dietary advice from another healthcare professional before their appointment with the dietitian, leading to a significant reduction in their dietary fat intake. 62 patients who were eligible for inclusion had an initial appointment with a dietitian and received low-fat dietary advice. However, 22 of these patients were not included in the service evaluation due to the following reasons; no attendance for follow up $(n=9)$, delay in follow up $(n=8)$, follow up undertaken over the phone $(n=2)$ and/or patients unable to rate

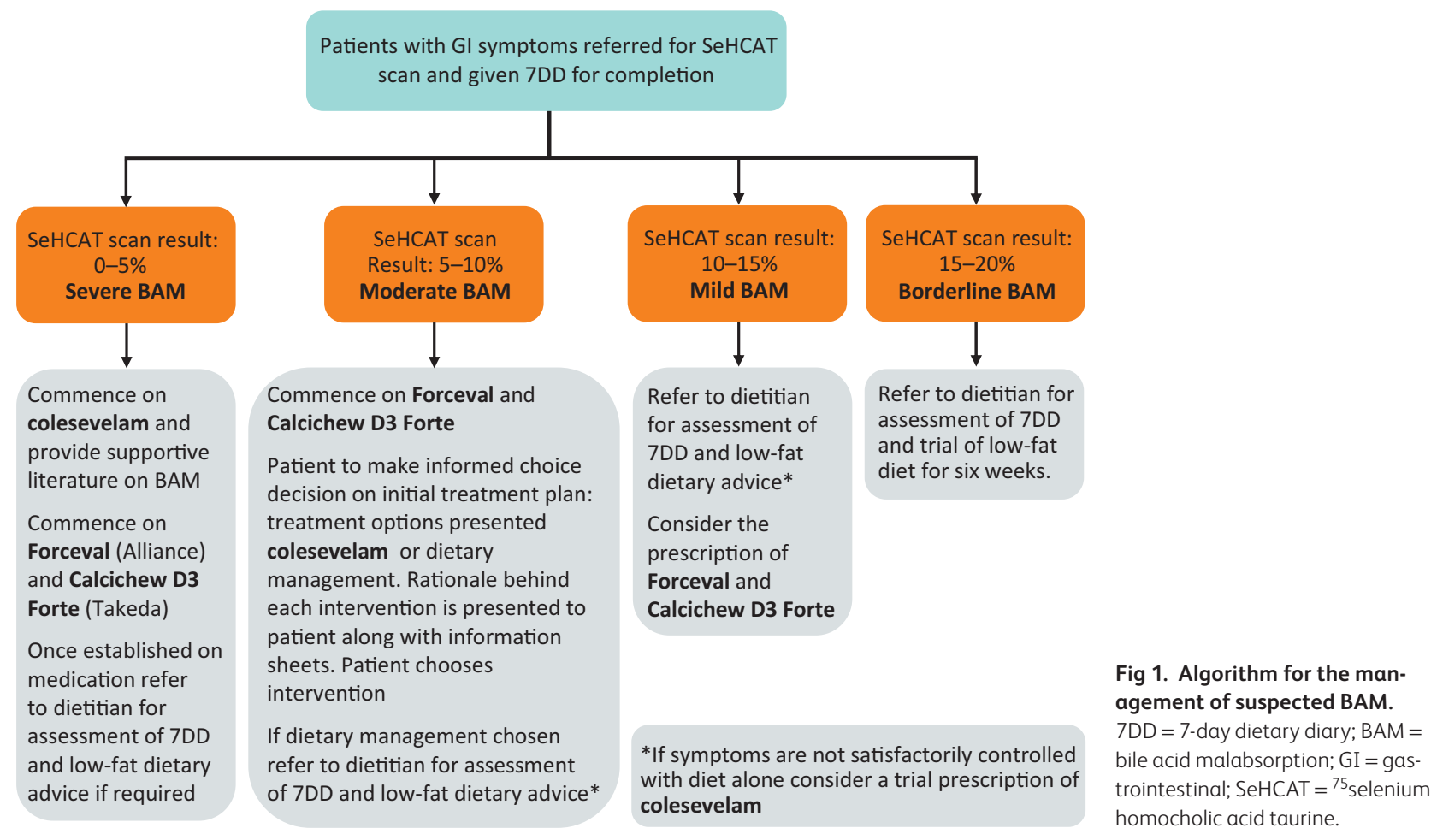


Table 1. Characteristics of study subjects.

\begin{tabular}{|c|c|}
\hline Characteristic & Value \\
\hline Male, n (\%) & $20(50.0)$ \\
\hline Female, $\mathrm{n}(\%)$ & $20(50.0)$ \\
\hline Age in years, mean (range) [SD] & $61(22-90)[12]$ \\
\hline Weight in kg, mean (range) [SD] & $71.2(32.7-109.3)[18.3]$ \\
\hline $\begin{array}{l}\text { Body mass index in } \mathrm{kg} / \mathrm{m}^{2} \text {, mean } \\
\text { (range) [SD] }\end{array}$ & $25.5(12.8-38.1)[5.2]$ \\
\hline \multicolumn{2}{|l|}{ Treatment } \\
\hline Previous GI surgery, n (\%) & $22(55.0)$ \\
\hline GI luminal surgery, $\mathrm{n}(\%)^{\mathrm{a}}$ & $15(37.5)$ \\
\hline Cholecystectomy, n (\%) & $7(17.5)$ \\
\hline \multicolumn{2}{|l|}{ Additional diagnoses, n (\%) } \\
\hline Pancreatic insufficiency, n ( \%) & $5(12.5)$ \\
\hline $\begin{array}{l}\text { Small intestinal bacterial overgrowth, } \\
\mathrm{n}(\%)\end{array}$ & $13(32.5)$ \\
\hline Using a bile acid sequestrant, $\mathrm{n}(\%$ ) & $25(62.5)$ \\
\hline \multicolumn{2}{|l|}{ SeHCAT 7-day retention, n ( \% ) } \\
\hline Severe: $0-<5 \%$ & $20(50.0)$ \\
\hline Moderate: $5-<10 \%$ & $7(17.5)$ \\
\hline Mild: $10-<15 \%$ & $10(25.0)$ \\
\hline Borderline: 15 - 20\% & $3(7.5)$ \\
\hline \multicolumn{2}{|c|}{$\begin{array}{l}{ }^{a} \text { surgical procedures for GI luminal surgery: 40-cm ileum and caecum resected; } \\
\text { gastrojejunostomy and ileocolic bypass, length resected unknown; ileocolic } \\
\text { resection, length resected unknown; cholescystectomy and small bowel } \\
\text { resection, length unknown; } 25-\mathrm{cm} \text { jejunum, } 25 \text {-cm ileum and right colon } \\
\text { removed; gastrectomy and splenectomy; } 30-\mathrm{cm} \text { terminal ileum resected; right } \\
\text { hemicolectomy, length resected unknown; rectal surgery, anterior resection only; } \\
\text { 8-cm terminal ileum, 70-cm distal jejunum, } 19-\mathrm{cm} \text { proximal jejunum; ileal } \\
\text { surgery, extent unknown; } 25-\mathrm{cm} \text { small bowel resected and right hemicolectomy; } \\
\text { right hemicolectomy, } 16-\mathrm{cm} \text { terminal ileum, caecum and } 57.5-\mathrm{cm} \text { colon; total } \\
\text { mesorectal excision; previous gastric bypass. GI = gastrointestinal; SD = } \\
\text { standard deviation; SeHCAT = }{ }^{75} \text { selenium homocholic acid taurine. }\end{array}$} \\
\hline
\end{tabular}

symptoms $(n=3)$. The mean length of time between with first appointment with the dietitian and follow up was 7.9 weeks (range 3-20).

\section{Symptom rating}

Table 2 shows the number of patients reporting each GI symptom and the significance of the change in the GI symptom after the low-fat dietary intervention. After dietary intervention, the median scores for all symptoms decreased. The change was statistically significant $(\mathrm{p} \leq 0.01-0.05)$ for all symptoms except nausea/vomiting, heartburn/acid reflux, belching or burping, feeling of incomplete evacuation and woken from sleep to open bowels.

\section{Dietary fat}

The mean dietary fat intake decreased from an initial mean intake of $62.3 \mathrm{~g}$ (median 58.9; range 34.5-100.8) fat to $42.2 \mathrm{~g}$ (median 39.1; range 24.5-80.8) fat after dietary intervention $(\mathrm{p} \leq 0.01)$. The mean dietary fibre intake was $14.8 \mathrm{~g}$ (median
13.8; range 6.10-32) at the first consultation and $14.4 \mathrm{~g}$ (median 13.6; range 4.40-34.70) at follow up ( $\mathrm{p}=$ not significant). $62.5 \%$ $(n=25)$ of patients had made all of the advised dietary changes advised and $70 \%(\mathrm{n}=28)$ had a dietary fat intake within $>90 \%$ of the dietary fat intake advised.

\section{Discussion}

This prospective study shows that after a low-fat dietary intervention, the median rating scores of all GI symptoms reported by patients with a SeHCAT scan result $<20 \%$ decreased. During the intervention period patients reduced their mean dietary fat intake by one-third. Specifically, there was a significant reduction in median symptom rating for urgency, bloating, lack of control and frequency of opening bowels $(\mathrm{p} \leq 0.01)$. In addition, there was a reduction in median symptom rating for flatulence, abdominal pain, greasy/pale stool and abdominal gurgling $(\mathrm{p} \leq 0.05)$.

This study diagnosed BAM using the SeHCAT scan test ${ }^{19,23}$ in patients attending a gastroenterology clinic who were experiencing a range of GI symptoms. Other diagnoses where excluded or treated by following a management algorithm. ${ }^{24}$ Patients were established on medication, if required, prior to the initiation of the dietary intervention. There was no statistically significant change in dietary fibre intake after dietary intervention which could have potentially acted as confounding factors.

Some experts would not consider treating patients with a SeHCAT score of $15-20 \%$ as they would consider this 'normal', however, by excluding these patients it would dilute any benefit of intervention. The authors consider BAM as a 'continuum' and it is not realistic to think that a single cut-off score is universally applicable. This was not a blinded study and patients acted as their own controls. One-third of the participants did not attend follow up which may raise questions about the applicability of this intervention, but no data were collected regarding the reasons for non-attendance.

Previous studies were undertaken over 20 years ago in predominately female populations and involved small numbers of patients receiving multiple concurrent interventions. ${ }^{20,21,25}$ This study is significantly larger, includes both men and women, and does not exclude patients with previous GI conditions or surgery. Adherence to the low-fat diet was also systematically assessed with a $7 \mathrm{DD}$, by recording symptoms before and after dietary intervention in patients in whom bile acid sequestrant dose was stable. 7DDs have a superior accuracy compared with other methods such as 24-hour dietary recall and food frequency questionnaires. ${ }^{26}$ All food diaries were analysed by one dietitian, which has been shown to improve reliability of dietary intake assessment. ${ }^{26}$ The dietary intervention used in this study has previously been shown to be an achievable low-fat intake which patients can follow long term. ${ }^{28}$ For an individual consuming 1,800 calories per day this equates to $40 \mathrm{~g}$ fat, as used in previous studies. ${ }^{20,25}$

Bile acid sequentrants or binders have been used in the treatment of BAM for over 40 years and can work by forming a complex with bile acids in the small intestine, and thus help to prevent the effects of free bile acids in the colon. ${ }^{17,19,29}$ The bile acid binder tablet used in this study, colesevelam, has been shown to have more acceptable palatability and a higher affinity for binding bile than a resin-based binder. ${ }^{17,29}$ 
Table 2. Number of symptoms reported by patients and statistical significance of change in GI symptoms after dietary intervention.

\begin{tabular}{|c|c|c|c|c|c|c|}
\hline Symptom & n (\%) & $\begin{array}{l}\text { Median score } \\
\text { first appointment }\end{array}$ & $\begin{array}{l}\text { Median score } \\
\text { follow-up } \\
\text { appointment }\end{array}$ & $\begin{array}{l}\text { IQR first } \\
\text { appointment }\end{array}$ & $\begin{array}{l}\text { IQR follow-up } \\
\text { appointment }\end{array}$ & $P$ value \\
\hline Urgency to open bowels & $33(83)$ & 8 & 5 & $7-10$ & $3-6$ & b \\
\hline Abdominal bloating & $17(43)$ & 7 & 5 & $5-9$ & $2-7$ & b \\
\hline Bowel frequency & $17(43)$ & 8 & 5 & $7-10$ & $4-7$ & b \\
\hline Lack of control & $16(40)$ & 9 & 6 & $7-10$ & $4-7$ & b \\
\hline Flatulence & $16(40)$ & 7 & 6 & $5-9$ & $3-7$ & a \\
\hline Abdominal pain & $15(38)$ & 8 & 3 & $4-10$ & $2-7$ & a \\
\hline Steatorrhoea & $9(23)$ & 8 & 3 & $4-9$ & $2-6$ & a \\
\hline Abdominal gurgling & $8(20)$ & 8 & 6 & $5-10$ & $3-7$ & a \\
\hline Nocturnal defaecation & $11(28)$ & 7 & 5 & $5-8$ & $3-6$ & ns \\
\hline Incomplete evacuation & $10(25)$ & 6 & 5 & $4-10$ & $2-7$ & ns \\
\hline Belching & $8(20)$ & 6 & 4 & $5-7$ & $2-6$ & ns \\
\hline Nausea or vomiting & $5(13)$ & 10 & 8 & $7-10$ & $4-10$ & ns \\
\hline Heartburn/acid reflux & $5(13)$ & 3 & 2 & $3-9$ & $2-5$ & ns \\
\hline
\end{tabular}

One-third of people with a diagnosis of IBS-D actually have primary BAD; this equates to approximately half a million people in the UK. ${ }^{3,10}$ In addition, there are significant, but as yet unquantified numbers of patients with acquired BAM after treatment for Crohn's disease or for cancer. This simple dietary intervention led to a statistically significant improvement in a range of GI symptoms in patients diagnosed with BAM detected by a SeHCAT scan. When one considers the impact of BAM to both the individual and the economy, this simple dietary intervention has the potential to have a widely beneficial effect. The potential use of dietary fat manipulation in the management of IBS-D or in those with diarrhoea after cancer treatment due to BAM has so far been overlooked in national guidelines. ${ }^{3,9}$

\section{Conclusion}

BAM is a cause for GI symptoms in around half a million people who are currently being treated for IBS-D in the NHS. This study has demonstrated that the use of low-fat dietary interventions in patients with a SeHCAT scan result $<20 \%$ leads to clinically important improvement in GI symptoms and should be widely used.

\section{Competing interests}

HJNA has acted as a paid consultant for GE, manufacturers of SeHCAT and for Sanofi Aventis, manufacturers of colesevelam.

\section{Funding}

This study was undertaken at the Royal Marsden NHS Foundation Trust which received a proportion of its funding from the NHS Executive; the views expressed in this publication are those of the authors and not necessarily those of the NHS Executive. We acknowledge NHS funding to the NIHR Biomedical Research
Centre. A portion of LW, AM and JA salaries are funded by Macmillan Cancer Support.

\section{References}

1 Lovell RM, Ford AC. Global prevalence of and risk factors for irritable bowel syndrome: a meta-analysis. Clin Gastroenterol Hepatol 2012;10:712-21.

2 National Insitute for Health and Clinical Excellence. Irritable bowel syndrome in adults: diagnosis and management of irritable bowel syndrome in primary care (CG61). London: NICE, 2008. Available online at http://guidance.nice.org.uk/CG61 [Accessed 30 July 2015].

3 Maxion-Bergemann S, Thielecke F, Abel F, Bergemann R. Cost of irritable bowel syndrome in the UK and US. Pharmacoeconomics 2006;24:21-37

4 Pare P, Gray J, Lam S, Balshaw R et al. Health-related quality of life, work productivity and health care resource utilization of subjects with irritable bowel syndrome: baseline results from LOGIC (longitudinal outcomes study of gastrointestinal symptoms in Canada) a naturalistic study. Clin Ther 2006; 28:1726-35.

5 Grundman O, Yoon SJ. Irritable bowel syndrome: epidemiology, diagnosis and treatment: an update for health-care practitioners. J Gastroenterol Hepatol 2010;25:619-99.

6 Andrae DA, Patrick DL, Drossman DA, Covington PS. Evaluation of the irritable bowel syndrome quality of life (IBS-QOL) questionnaire in diarrheal-predominant irritable bowel syndrome patients. Health Qual Life Outcomes 2013;11:1-12.

7 Jellema P, van der Windt DA, Schellevis FG, van der Horst HE. Systematic review: accuracy of symptom-based criteria for diagnosis of irritable bowel syndrome in primary care. Aliment Pharmacol Ther 2009;30:695-706.

8 National Insitute for Health and Clinical Excellence. SeHCAT (tauroselcholic [75 selenium] acid) for the investigation of diarrhoea due to bile acid malabsorption in people with diarrhoea predominant irritable bowel syndrome (IBS-D) or crohn's disease without ileal resection (DG7). London: NICE, 2012. Available 
online at http://guidance.nice.org.uk/dg7 [Accessed 30 July 2015].

9 Wedlake L, A'Hern R, Russell D et al. Systematic review: the prevalence of idiopathic bile acid malabsorption as diagnosed by SeHCAT scanning in patients with diarrhoea-predominant irritable bowel syndrome. Aliment Pharmacol Ther 2009;30:707-17.

10 Ford GA, Preece JD, Davies IH, Wilkinson SP. Use of SeHCAT test in the investigation of diarrhoea. Postgrad Med J 1992;68:272-6.

11 Gracie DJ, Kane JS, Mumtaz S et al. Prevalence of and predictors of bile acid malabsorption in outpatients with chronic diarrhoea. Neurogastroenterol Motil 2012;24:983-9.

12 Costarelli V, Sanders TAB. Acute effects of dietary fat composition on postprandial plasma bile acid and cholecystokinin concentrations in healthy premenopausal women. Br J Nutr 2001;86:471-7.

13 Bisschop PH, Bandsma RHJ, Stellard F et al. Low-fat, highcarbohydrate ad high-fat, low-carbohyrate diets decrease primary bile acid synthesis in humans. Am J Clin Nutr 2004;79:570-6.

14 Reddy BS, Engle A, Simi B et al. Effect of low-fat, highcarbohydrate, high-fiber diet on fecal bile acids and neutral sterols. Prev Med 1988;17:432-9.

15 Hofmann AF, Mangeldorf DJ, Kliewer SA. Chronic diarrhoea due to excessive bile acid synthesis and not defective ileal transport: A new syndrome of defective FGF19 release. Clin Gastroenterol Hepatol 2009;7:1151-4.

16 Walters JRF, Tasleem AM, Omer OS et al. A new mechanism for bile acid diarrhoea: Defective feedback inhibition of bile acid biosynthesis. Clin Gastroenterol Hepatol 2009;7:1189-94.

17 Walters JRF, Pattni SS. Managing bile acid diarrhoea. Therap Adv Gastroenterol 2010;3:349-57.

18 Wedlake L, Andreyev J. Bile acid malabsorption. In: Hawkey CJ, Bosch J, Richler J, Guadalupe Garcia TSAO (eds), Textbook of clinical gastroenterology and hepatology. Oxford: Wiley Blackwell, 2012:311-7.

19 Pattni S, Walters JRF. Recent advances in the understanding of bile acid malabsorption. Brit Med Bull 2009;92:79-93.

20 Bosaeus I, Andersson H, Nystrom C. Effect of a low-fat diet on bile salt excretion and diarrhoea in the gastrointestinal radiation syndrome. Acta Radiol Oncol 1979;18:460-4.
21 Danielsson A, Nyhlin H, Persson H, Stenling R, Suhr O. Chronic diarhhoea after radiotherapy for gynaecological cancer: occurrence and aetiology. Gut 1991;32:1180-7.

22 Zubek J, White R. An audit investigating the efficacy of the low FODMAP diet in improving symptoms in patients with functional gastro-intestinal symptoms. Gut 2012;61:A86.

23 Sciarretta G, Vicini G, Fagioli G et al. Use of 23-selena-25-homochololytaurine to detect bile acid malabsorption in patients with ileal dysfunction and diarrhoea. Gastroenterol 1986;91:1-9.

24 Andreyev HJN, Benton BE, Lalji A et al. Algorithm-based management of patients with gastrointestinal symptoms in patients after pelvic radiation treatment (ORBIT): a randomized controlled trial. Lancet 2013;13:61345-8.

25 Bye A, Kaasa S, Ose T, Sundfor K, Trope C. The influence of low fat, low lactose diet on diarrhea during pelvic radiotherapy. Clin Nut 1992; 11:147-53.

26 Bingham SA, Gill C, Welch A et al. Validation of dietary assessment methods in the UK arm of EPIC using weighed records, and 24-hour urinary nitrogen and potassium and serum vitamin $\mathrm{C}$ and carotenoids as biomarkers. Int J Epidemiol 1997;26:s137-51.

27 Braakhuis AJ, Meredith K, Cox GR, Hopkins WG, Burke LM. Variability in estimation of self-reported dietary intake data from elite athletes resulting from coding by different sports dietitians. Int J Sport Nutr Exerc Metab 2003;13:152-65.

28 Chlebowski RT, Blackburn GL, Thomason CA et al. Dietary fat reduction and breast cancer outcome: interim efficacy results from the women's intervention nutrition study. J Natl Cancer Inst 2006;98:1767-76.

29 Wedlake L, Thomas K, Lalji A, Anagnostopoulos C, Andreyev HJN. Effectiveness and tolerability of colesevelam hydrochloride for bile acid malabsorption in patients with cancer: a retrospective chart review and patient questionnaire. Clin Ther 2009b;31:2549-58.

\section{Address for correspondence: Dr C Shaw, Department of} Nutrition and Dietetics, The Royal Marsden NHS Foundation Trust, Fulham Road, London SW3 6JJ, UK.

Email: clare.shaw@rmh.nhs.uk

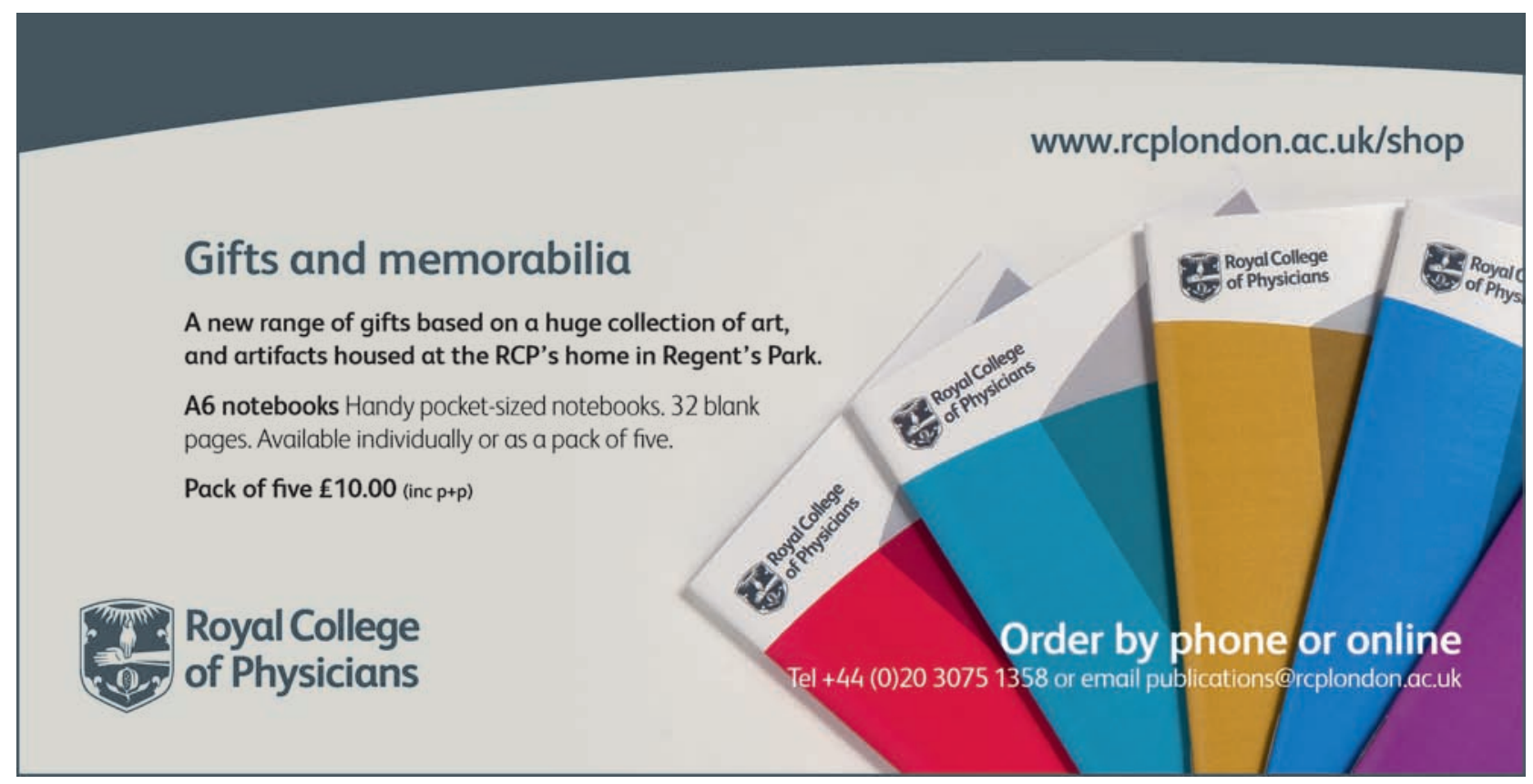

